We might sum up our findings as follows: When two steam vessels are crossing so as to involve risk of collision and observe each other upon their radar screens at a good distance apart, the vessel which has the other upon her starboard hand and forward of her beam shall keep out of the way by altering course to starboard sufficiently to pass astern of the other. The other vessel may reduce speed, but she shall not alter course to port.

'(2) That the international code signal " $\mathrm{C}$ " (Yes) in morse on the whistle should signify in fog "I am using radar", and should be used in place of every third blast required by Article 15. '

Sound is notoriously difficult to locate in fog and it could never be certain that a vessel sounding ' $\mathrm{C}$ ' apparently in a particular direction was in fact the one appearing upon the radar screen. It seems more likely that this signal would mislead and confuse rather than help.

'(3) The establishment on charts of a traffic dividing mark at a suitable distance off headlands or other turning points: ships with land on their starboard hand to keep inside of it and those with the land on their port hand to keep outside of it.'

This seems both desirable and practicable in crowded traffic lanes, particularly in areas where Decca renders it possible for very accurate courses to be followed whatever the visibility.

\title{
Visual Judgments in Motion
}

THE following discussion, here printed in summary, took place on Mr. E. S. Calvert's paper 'Visual Judgments in Motion', which was presented at an Ordinary Meeting of the Institute on 2 I May. The chairman was Air Chief Marshal the Hon. Sir Ralph Cochrane, G.B.E., K.C.B., A.F.C. The paper was printed in the last number of the Journal (July).

The Chairman: Am I right in thinking that I.C.A.O. have accepted the Crossbar system of lighting? Is it the normal pattern in international airports?

Mr. E. S. CaLverT: The I.C.A.O. standard calls for a centre line and Crossbar pattern, but is worded in such a way as to include patterns which differ in detail from that used in this country. This was done to meet the wishes of the Americans and Dutch. The Americans use one large bar at 1000 feet from the threshold, and short bars of equal length in the rest of the system. The Dutch use long bars at the same spacing as in this country but of equal length. These differences are important only in visual ranges of half a mile or less.

Mr. G. W. Stallibrass (Ministry of Transport and Civil Aviation): There are a number of things that need finding out in regard to runway lighting, and no doubt work is being carried out in more than one Ministry. Could $\mathrm{Mr}$. Calvert give some indication as to what should be the lateral spacing, assuming there has to be some form of elevated lighting? There has been considerable variance of opinion in that regard. Papers have been published suggesting that the best indication for the pilot from the angular point of view is if the lateral spacing is no more than about $\mathrm{I}_{5} \mathrm{O}$ feet; there is a slight fall when the spacing is 200 feet and indication falls very rapidly at more than 250 feet. The Ministry of Transport and Civil Aviation are interested because we are probably going to use elevated-type runway lighting rather than the flush-type. 
There is another point which rather confirms that the main factor is not so much the number of lights one can see as the length of lighting visible. There have been extraordinary variations in the spacing, longitudinally, of the lights in a runway lighting system. On occasions, and for unavoidable reasons, spacings in this country have varied from 400 feet to 80 feet at different aerodromes, without apparently causing comment from those using them. This indicates that when the operating visibility is well above, say, 1200 feet, pilots do not mind, as long as they can see the length of lights, how many lights there are in it.

More than one body is becoming worried about the increasing extent to which aircraft are under-shooting. It may be either that undershoots are increasing or that we are finding out about more of them. We have found tyre marks in quite unexpected places on approaches to runways, and there have been incidents in other countries as well, in which it has been clear that the pilot touched down unnecessarily short in relation to the length of runway available. We have taken certain elementary precautions, such as installing frangible approach lights, but the fact remains that the pilot is not getting all the indication he requires. It may be that the indication he needs now is different because of different characteristics of modern aircraft on final approach.

As to the value of illuminated angle of approach indicators, they were used during the recent war, but the pattern then used is not acceptable under peacetime conditions. For what it is worth, another pattern is being developed for us for experimental use. I should like to hear from Mr. Calvert what he thinks of the value of this kind of indicator?

Mr. Calvert: The spacing between the rows of runway lights has a large effect on the indication of lateral error in bad visibility. For instance, at landing the sensitivity of the indication, i.e. the change in the perspective angle per foot of deviation from the centre line, is about 25 times better for a centre line than for two lines spaced 200 feet apart. In fact, to obtain good directional indications on the landing run in bad visibility a centre line must be used.

The effect on the height indications is more complicated, because these are derived both from the perspective angle and the vertical component of the streamer velocity. In my view the best arrangement for all-weather runways is a runway 200 feet wide with elevated lights of high intensity along the edges, flush lights of moderate intensity along the middle, and stub bars on the outside of the edge lights. It is important that the transverse spacing of the lights in the stub bars should be the same as in the bars of the approach lighting system, as with small lights this is the only method of providing the textural indications which are so necessary to prevent loss of ground plane in marginal conditions. The longitudinal spacing between the runway lights is of much less importance. In my view it should be standardized at about 100 feet for all-weather runways, and about 200 feet for other runways.

As regards undershoots, my information is that these have been very few on the Crossbar system, as might be expected from the fact that the streamer velocities of the bars provide an excellent indication of height. My own view is that the best method of reducing undershoots is to install a short-approach lighting system, say one 1500 feet long with two crossbars; I suggested this at the last meeting of the A.G.A. Division of I.C.A.O. If this is too costly, or the terrain does not permit it, then all that can be done is to use the two devices mentioned in the last paragraph of the paper.

Captain P. BRessey (B.E.A.): In his paper Mr. Calvert said that his present 
theory is that the minimum amount of visual guidance the pilot requires can be described solely by the angle of the visual segment observed. Up to now the generally accepted argument, attributed to Captain Jenks of C.A.A., has been that the minimum amount of visual guidance needed (always supposing the pilot to be working on a good pattern in the first place) is that which will enable him to focus on one light for a minimum period of time; he must be able, if necessary, to keep his eye on one light for three seconds. Therefore, the minimum visual segment needed to see enough of the lighting system during an approach will vary according to the speed of the approach over the ground. $\mathrm{Mr}$. Calvert said that would be a small angle, and that is so for most cockpits where the cutoff is at about the same point; but if in a fast plane the pilot sits up in a perspex bubble right in the nose of the plane so that he can see almost straight down, then the angle of visual segment which will be subtended in poor visibility (say from $80^{\circ}$ to $70^{\circ}$, giving a $10^{\circ}$ angle) will make the approach much more difficult.

Mr. Calvert said he would like to hear a discussion on the artificial horizon: whether the aeroplane should stay fixed and the horizon bar move or the horizon bar remain fixed and aeroplane move. Pilots are largely creatures of habit; they have become used to the moving bar and if things are immediately reversed confusion will be caused. This was brought home to me recently in my own airline when we changed over our instrumentation from the old Sperry directional gyro to the CL 2 compass, which gave completely different instrument indication of change of heading. The directional gyro was a vertical drum which revolved behind a line drawn on the glass in front of it. On a CL 2 compass, the compass needle moved round a circular face. The pilot was looking at the thing in plan view instead of edge-on. I for one had considerable difficulty in sorting out this information when we were changing over to this type of instrument. After one had been concentrating on it for some time one got confused, and towards the end of a long QDM let-down, one would often turn the wrong way for a moment. One immediately realized the mistake, but the new form of heading presentation did cause this difficulty until one was accustomed to it, and I think the confusion would be far greater with a change of attitude presentation.

Before a change was contemplated in such an important instrument as the artificial horizon, I think it would be necessary to take a batch of new pilots, and train half on one type of instrument, and half on the other, and then compare the results. If the change were made to moving aeroplane presentation, I feel the older pilots would have a confusion period which might last for quite a time.

Mr. Calvert: The theory I have put forward is that complete guidance is not obtained until the furthermost point $P$ which the pilot can see is within a certain angle measured downwards from the aiming point A. For example, if the aircraft is on a $3^{\circ}$ glide slope, then $A$ is $3^{\circ}$ below the horizon. I have supposed that $\mathrm{P}$ must be not more than $2^{\circ}$ below that, i.e. not more than $5^{\circ}$ below the horizon. The angular amount of pattern seen when complete guidance is obtained is therefore the angle between $P$ and the cut-off line, and I have supposed that this must be more than $3^{\circ}$, i.e. the downward view must be at least $8^{\circ}$. It is, of course, highly desirable that some guidance, even if only partial, be obtained as early as possible, and for this the angle between $P$ and the cut-off line must be large, say $10^{\circ}$. This means a downward view in the approach of about $15^{\circ}$. The right angle between the crossbar and the centre line is as necessary as ever, 
because the above values only hold for a good pattern, i.e. one with crossbars. If there are no crossbars, then $\mathrm{P}$ must be closer to the horizon, which means very long visual ranges. This largely explains the low values of landing success apparently obtained in the U.S.

My chief objection to the simple theory put forward by Captain Jenks is that. it assumes that a certain length of visual segment gives the same amount of guidance irrespective of its angular distance below the horizon. If it were true that 600 feet of pattern seen ahead of the cut-off line provided complete guidance then, assuming a critical height of 200 feet, aircraft with downward views of $25^{\circ}$ would be able to land with a visual range of 1029 feet, but aircraft with downward views of $10^{\circ}$ would require 1734 feet. Actually the difference in operating limits would be nothing like as great as this, because the pilots of both types of aircraft would obtain full guidance at about the same time. A further objection to Captain Jenks' theory is that any given length of pattern must at some range subtend such a small angle that its relation to the horizon cannot be determined with sufficient accuracy. Both objections are overcome by taking an angular segment of pattern at an angular distance below the horizon.

Mr. J. BRISCOE (Ministry of Transport and Civil Aviation): If the cockpit cutoff is to remain as on most present aircraft, all forms of aircraft-and I include helicopters as but one form of slow-landing aircraft-have got to approach at the same sort of gradient as high-speed aircraft, and the difficulty of finding aerodrome sites clear of obstructed approaches will be met. For helicopter operations we shall be in a sad way for finding sites if such a clearance is needed. Also, helicopter sites are small, and it will be difficult to place any form of approach lighting outside the confines of the site. Has Mr. Calvert given thought to the problem of providing approach lighting for helicopters totally within the site of the movement area?

Mr. Calvert: The downward view required in any type of aircraft depends on the angular distance of the aiming point below the horizon. Since this is equal to the angle of approach, and the helicopter has a steep angle of approach, it follows that the helicopter must have a large downward view. I have not been engaged on the design of visual aids for helicopters, but as they can approach the landing ground from any direction, it may be that the aids should take the form of concentric circles with radial lines.

Mr. A. H. Jessell (Ministry of Transport and Civil Aviation): Mr. Calvert explained at the end of his talk that when going towards a point all the other points in the field of vision appear to be moving away from one. To help the pilot make an approach to a runway and touch down more or less at the same point, it would seem to follow that there should be clearly defined lights or markings beyond the point of touch-down. These would move away faster as one approached it, and the pilot would still be able to see his aiming point after the lights on the approach had gone out of his field of vision. If that is correct, does it follow that the approach lighting system to be of full value to enable a pilot to touch down at the right place on the runway should continue beyond the point of touch-down in more or less the same manner as before?

Mr. CAlvert: The touch-down point is picked out by observing the apparent movement of whatever objects happen to be in the field of view, so there is no necessity to have the same pattern on the runway as in the approach. Indeed, it is essential to have a change of pattern to distinguish the paved area from the unpaved area. The touch-down point is never easy to judge, and a visual approach 
must necessarily be a series of successively closer approximations to the desired path.

Another Member: I was interested in the visual perspective provided by the touch-down system with crossbars of different and increasing lengths and also in the number of crossbars necessary to provide the required guide slope and distance. It would be interesting to know if there is any correlation between distortion perspective angle and the real perspective angle by means of crossbar alteration; also to know the number of crossbars necessary to provide distance information from the aiming point. What guide slope information was provided by the taper?

Mr. Calvert: The original reason for using tapering bars was to indicate whether or not the aircraft was overshooting or undershooting the aiming point. I think they do this to a small extent, but the indication is poor, and I doubt if it is possible to provide a good natural indication with any pattern. However, if the pilot has already set his rate of descent by means of the radio aid, then all the approach lights have to do is to help him to carry on until he sees the threshold of the runway. In the limiting conditions, if he picks up the lights at 200 feet, he will see the threshold at 120 feet, so he has had poor aiming point guidance for only about 8 seconds. He is able to carry on through this period because the apparent motion of the bars tells him whether or not he is overshooting the furthermost bar that he can see, and whether or not he is at a safe height. Operational experience indicates that the pilot must see a minimum of two bars in order to do this without undue strain.

However, even if the tapering bars do not give a good indication of the touchdown point, they do insure that the bank indication shall always be adequate. If bars of equal length are used, the angular subtense decreases with height, and so does the sensitivity of the bank indication. The bank indication is therefore worst at the transition height where it is most needed.

Mr. O. W. Neumark (private pilot): Could Mr. Calvert say whether any tests have been made varying the approach speed by using different aircraft; for example, a Meteor coming in at 150 miles an hour and a Miles Gemini at 35 miles an hour in the same critical visibility conditions?

Mr. Calvert: My view is that approach speeds cannot be safely increased beyond a certain value which depends on the skill of the pilot and the manceuvrability of the aircraft, because the higher the speed the more accurately the heading error has to be judged. In any given visibility there is a limit to the accuracy with which this judgment can be made. It would therefore seem that if approach speeds go up and manœuvrability goes down, the alternatives may be to install automatic landing or confine operations to good visibility conditions.

\section{A Fix by Total Solar Eclipse from D. H. Sadler}

A TOTAL eclipse of the Sun provides an opportunity, rare though it may be, of obtaining an instantaneous fix from the Sun alone. Eclipses vary greatly in character, in position on the Earth, in the width of the path of totality, in the duration, and also in the direction of the path. However, the shadow of the Moon cast by the Sun is always a right circular cone which, in the case of a total 